\title{
GÊNERO E SEXUALIDADE NA BNCC: POSSIBILIDADES PARA IMPLEMENAÇÃO DA DISCIPLINA EDUCAÇÃO PARA SEXAULIDADE NA EDUCAÇÃo BÁSICA
}

\author{
GENDER AND SEXUALITY AT BNCC: POSSIBILITIES FOR IMPLEMENTING THE SEXUALITY \\ EDUCATION SUBJECT IN BASIC EDUCATION
}

https://orcid.org/0000-0003-4385-8093Luiz Carlos Marinho de Araújo A

${ }^{\text {A}}$ Universidade Estadual do Oeste do Paraná (UNIOESTE), Cascavel, PR, Brasil

Recebido em: 17 jul. 2021 | Aceito em:21 dez. 2021

Correspondência: Luiz Carlos Marinho de Araújo (marinhoaluiz@hotmail.com)

\begin{abstract}
Resumo
Neste artigo, propõe-se a inserção da disciplina "Educação para sexualidade" como componente facultativo do currículo da Educação Básica, tendo como ponto de partida o negacionismo das discussões sobre gênero e sexualidade na Base Nacional Comum Curricular - BNCC, visto que na última versão do documento o termo foi eliminado, o que tem dificultado as instituições de ensino de criarem estratégias que possibilitem a inserção dessa temática no ambiente escolar. É a partir dessa omissão acerca do conceito de gênero e sexualidade que essa pesquisa foi desenvolvida, tendo como marco o questionamento: qual(is) a(s) possibilidade(s) de inserir a Educação para sexualidade - EPS como componente curricular eletivo na Educação Básica? O intuito deste estudo é apresentar uma Proposta Curricular para incluir a temática acerca da Educação para a sexualidade como uma disciplina na parte diversificada do currículo. Trata-se, portanto, de uma pesquisa de natureza qualitativa que usou como técnica a análise documental, o fichamento cronológico como instrumento de constituição dos dados, e a análise do "corpus" para as etapas da Tríade metodológica, ambos os procedimentos fazem parte do Método Pragmático: da construção à [re]construção dos dados (ARAÚJO, 2021). Teoricamente, os dados foram analisados e embasados em autoras como Louro (1997; 2000; 2008), Sabat (2001) e Butler (2014). Ao final, o estudo confirmou a omissão dos conceitos de gênero e sexualidade na atual BNCC, porém, viabilizou a criação de uma Proposta Curricular como estratégia para implementar discussões que contemplem as inquietações acerca de gênero e sexualidade nas turmas da Educação Básica.
\end{abstract}

Palavras-chave: Gênero e Sexualidade; Currículo; Orientação sexual.

\begin{abstract}
This article proposes the insertion of the subject "Education for sexuality" as an optional component of the Basic Education curriculum, taking as its starting point the denial of discussions on gender and sexuality in the Common National Curriculum Base - BNCC. As in the latest version of the document, the term was eliminated, which has contributed to the difficulties of educational institutions in creating strategies that enable the insertion of this theme in the school environment. It is from this omission about the concept of gender and sexuality that this research was developed, having as a framework the question: what is the possibility(s) of inserting Education for sexuality - EPS as an elective curricular component in Basic Education? The purpose of this study is to present a Curriculum Proposal to include the theme about Education for sexuality as a discipline in the diversified part of the curriculum. The qualitative research used as a technique the document analysis, the
\end{abstract}


chronological record as an instrument of data constitution, and the analysis of the "corpus" for the steps of the methodological Triad, both procedures are part of the Pragmatic Method. Data were analyzed and theoretically grounded, mainly by the authors Louro $(1997,2000$, 2008), Sabat (2001) and Butler (2014). The study confirmed the omission of the concepts of gender and sexuality in the current BNCC, however, it made possible the creation of a Curriculum Proposal as a strategy to implement discussions that address concerns about gender and sexuality in Basic Education classes.

Keywords:Gender and Sexuality; Resume; Sexual orientation.

\section{Prefácio}

Situando o leitor acerca da separação dos termos gênero, sexualidade e gênero e sexualidade no decorrer do texto.Optou-se por usar os termos em discussão de forma separada, por entender que ambos apresentam definições

e características distintas. Dessa maneira, os conceitos aparecerão: gênero, sexualidade e gênero e sexualidade.

Hodiernamente, discutir as inquietações relacionadas a gênero, sexualidade, gênero e sexualidade é, sem dúvida, uma necessidade não apenas do ambiente familiar. As instituições de ensino têm cada vez mais se tornado válvulas de escape para muitos estudantes que estão na fase da adolescência, onde os questionamentos sobre orientação sexual começam a surgir. Por vezes, muitas dúvidas estão diretamente ligadas aos próprios adolescentes que não encontram a abertura para dialogar sobre essas questõesno contexto ou ambiente familiar.

A pesquisa se deu na busca dos termos gênero, sexualidade, gênero e sexualidade nas três versões da Base Nacional Comum Curricular - BNCC (2015), (2016) e (2017).Os termos foram pesquisados separadamente para oportunizar ao leitor o delineamento de cada termo, visto que ambos apresentam acepções diferentes, porém se complementam ao se discutir as questões relacionadas à orientação sexual.

O termo gênero, passível de diversas interpretações nos campos das artes, da linguística e das ciências tem sua ampla definição confirmada no decorrer da busca nos documentos analisados, superando a ideia de gênero normativo apenas ligado ao masculino e feminino.

Assim,

[...] Supor que gênero sempre e exclusivamente significa as matrizes 'masculino' e 'feminino' é perder de vista o ponto crítico de que essa produção coerente e binária é contingente, que ela teve um custo, e que as permutações de gênero que não se 
encaixam nesse binarismo são tanto parte do gênero quanto seu exemplo mais normativo (BUTLER, 2014, p. 253).

Sexualidade, por sua vez, é um termo ainda vinculado diretamente ao sexo, ao prazer e à reprodução humana. Além disso, seu sentido é bastante camuflado nas discussões que permeiam inquietações sobre suas problemáticas. Isso tem contribuído para a propagação errônea do termo ou impossibilitado o diálogo entre as pessoas que relacionam o termo sexualidade sempre às questões do sexo. Dessa forma, normatiza o sexo como um prazer masculino e à reprodução da espécie, por meio do qual a figura feminina é vista apenas como oportunidade de manter a geração humana. Essa compreensão tem, ao longo dos anos, conseguindo superar a ideia da sexualidade como sexo, e da mulher como submissa ao homem no ato sexual.

As reflexões sobre gênero e sexualidade perpassam o normativo homem e mulher, e o prazer atrelado ao ato sexual. "A construção dos gêneros e das sexualidades dá-se através de inúmeras aprendizagens e práticas, insinua-se nas mais distintas situações, é empreendida de modo explícito ou dissimulado por um conjunto inesgotável de instâncias sociais e culturais" (LOURO, 2008, p. 18).

Neste artigo, as temáticas trazidas para discussão estão compiladas nas questões sobre orientação sexual propostas pelos Parâmetros Curriculares Nacionais - PCN de 1997, que a tem como um dos Temas transversais, porém fora excluído da versão final da Base Nacional Comum Curricular (2017). É dessa omissão apresentada na BNCC (2017) que emerge esta pesquisa, constituída a partir de uma palestra realizada em um Grupo de Pesquisa de uma Universidade Estadual do Paraná.

A pesquisa visou investigar uma problemática socioeducacional, tendo como referência a inquietação: qual(is) a(s) possibilidade(s) de inserir a Educação para sexualidade - EPS, como componente curricular eletiva na Educação Básica? A partir disso, objetiva-se apresentar uma Proposta Curricular para incluir a temática acerca da Educação para a sexualidade como uma disciplina na parte diversificada do currículo.

\section{Método de constituição dos dados}

A temática discutida neste artigo emerge após uma palestra proferida por um professor da Universidade Estadual da Bahia para um Grupo de Pesquisa de uma Universidade Estadual do Paraná, no dia 22 de junho de 2021. Dentre as diversas discussões que surgiram no decorrer da fala do professor, a ausência dos termos gênero e sexualidade na terceira e última versão 
da Base Nacional Comum Curricular - BNCC (2017) foi a mais polêmica, em virtude de o documento constituir-se como normativa para orientar as instituições de ensino no território nacional na elaboração de suas Propostas Pedagógicas e Curriculares. Diante dessa situação, aflorou-se determinado questionamento: de que maneira os profissionais da educação podem implementar ações direcionadas ao trabalho com gênero e sexualidade no cenário escolar,mesmo a BNCC não oportunizando discussões acerca da temática? Essa inquietação esteve em pauta durante toda a fala do referido professor.

Pensando nisso, o estudo tem como objetivo central apresentar estratégias curriculares que possibilitem os envolvidos com a educação nacional inserir reflexões sobre gênero e sexualidade no contexto escolar. A proposta é ampliar as discussões sobre a temática diante do silenciamento que a BNCC tem despertado nesses quatro anos de efetivação. Como ponto de partida do estudo, a pesquisa foi desenvolvida pelas orientações do Método Pragmático (MP) (ARAÚJO, 2021), que concede autonomia ao pesquisador para criar seus próprios mecanismos de efetivação de um estudo científico, seguindo o rigor metodológico de uma pesquisa científica.

O Método Pragmático possibilita que o investigador estruture seu desenho metodológico de forma criativa, colocando os dados como centralidade de toda a discussão, evitando que no percurso da pesquisa sejam eliminadas as temáticas emergentes do "corpus" (BARDIN, 2016). Assim, tendo a constituição dos dados como ponto de partida , o MP foi delineado por três etapas que compõem a Tríade metodológica no formato de espiral. Com base nisso, o pesquisador poderá, sempre que necessário, retomar a etapa anterior para aprofundar a análise dos dados. A Tríade metodológica CDR, proposta pelo Método Pragmático está organizada por três etapas - observar Figura 1 -, que se relacionam durante a análise dos dados, sendo elas: Construção, [Des]construção e [Re]construção - CDR dos dados (ARAÚJO, 2021, 74-81).

Figura 1: Método Pragmático para análise dos dados 


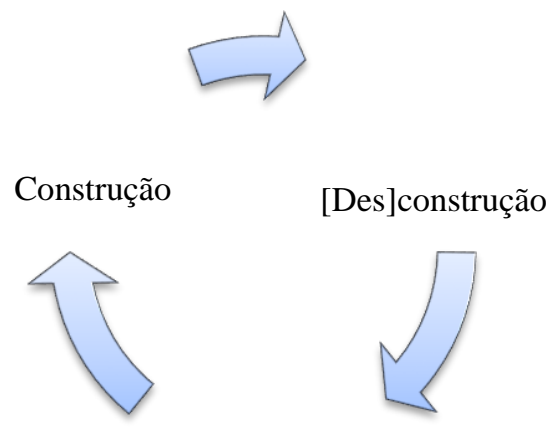

[Re]construção

Fonte: Dados da pesquisa.

$\mathrm{Na}$ primeira etapa, a da Construção, foi definida a abordagem, a técnica e o instrumento para constituição dos dados. Sendo assim, organizou-se um estudo de natureza qualitativa, com a análise documental como técnica e o fichamento cronológico como estratégia metodológica de desmontagemdo texto que constituiria o "corpus" para a etapa de análise dos dados. A pesquisa de abordagem qualitativa contém em seu arcabouço o estudo de "[...] um fenômeno [que] pode ser melhor compreendido no contexto em que ocorre e do qual é parte, devendo ser analisado numa perspectiva integrada" (GODOY, 1995, p. 21).

Um estudo qualitativo oportuniza que o pesquisador apresente discussões relevantes acerca do problema de pesquisa de forma a contribuir com as reflexões sobre o tema investigado. Godoy (1995, p. 21) ressalta que a pesquisa de "[...] abordagem qualitativa, enquanto exercício de pesquisa, não se apresenta como uma proposta rigidamente estruturada, ela permite que a imaginação e a criatividade levem os investigadores a propor trabalhos que explorem novos enfoques".

$\mathrm{Na}$ primeira etapa, ainda foi realizado um estudo documental nas três versões da BNCC (2015), (2016) e (2017), como tática para diagnosticar se as colocações que os membros do Grupo de Pesquisa da referida Universidade pontuaram acerca da omissão do termo gênero e sexualidade confirmavam-se. A análise documental,

Embora pouco explorada não só na área de educação como em outras áreas de ação social, [...] pode se constituir numa técnica valiosa de abordagem de dados qualitativos, seja complementado as informações obtidas por outras técnicas, seja desvelando aspectos novos de um tema ou problema (LÜDKE; ANDRÉ, 2020, p. $45)$.

Nesse sentido, Godoy (1995, p. 21) sublinha que "a pesquisa documental representa uma forma que pode se revestir de um caráter inovador, trazendo contribuições no estudo de 
alguns temas". Portanto, a intenção desta pesquisa é contribuir de forma pontual com as discussões que a Base Nacional Comum Curricular tem provocado no campo educacional, desde a sua concretização como documento oficial para normatizar o ensino brasileiro, desde 2017 até a presente data.

Em continuidade ao estudo, concretizou-se a etapa de [Des]construção dos dados, por meio da qual foi realizado um estudo nas três versões da BNCC, usando como recurso metodológico o fichamento, que tem a "função [..] de organizar ideias através do material consultado para a realização de uma pesquisa" (FRANCELIN, 2016, p. 122). Logo, o tipo de fichamento adotado foi o fichamento cronológico, pois consiste em apresentar informações pertinentes ao estudo de forma temporal.

O fichamento cronológico integra a segunda etapa do Método Pragmático [Des]construção dos dados (ARAÚJO, 2021). Dessa forma, realizou-se uma busca separada pelos termos gênero, sexualidade, gênero e sexualidade, nas três versões da BNCC. A intenção de separar a busca pelos termos em três momentos se deu em virtude de os conceitos isolados apresentarem distintos significados e, consequentemente, variadas interpretações. Para a realização da busca de informações referente aos três termos expostos acima, aplicou-se o comando $C t r l+F$, que tem a função de realizar uma busca rápida em documentos no formato Portable Document Format - PDF. Diante disso, as definições encontradas foram lançadas no fichamento cronológico de forma a subsidiar a etapa seguinte deste artigo.

$\mathrm{Na}$ etapa final, a de [Re]construção, os dados foram reconstruídos durante a análise, tendo como base as pesquisas de Louro (2020; 2008), Sabat (2001), etc. Na última etapa usouse como recurso para apresentar as discussões dos dados uma linha do tempo montada a partir das informações obtidas com a aplicação do fichamento cronológico, conforme a Figura 2. Com a realização das três etapas propostas pelo Método Pragmático, foi possível organizar uma análise a partir dos documentos pesquisados e estruturar algumas estratégias que podem ser usadas como prática pedagógica para incluir o tema gênero e sexualidade no ambiente escolar, mesmo a versão final da BNCC não contemplando essa possibilidade.

Na seção seguinte, isto é, na segunda etapa - [Des]construção -, os dados obtidos serão discutidos a partir das informações adquiridas no fichamento cronológico. Vale lembrar que tais dados estarão expostos na Figura 2, organizados cronologicamente pelo ano de cada versão do documento e as respectivas quantidades que os termos gênero, sexualidade, gênero e sexualidade aparecem nas três versões analisadas. O quantitativo referente a cada termo 
possibilita uma gama de reflexões em torno da problemática que será debatida posteriormente na terceira etapa - [Re]construção dos dados.

\section{Discussão a partir dos dados}

O ponto de partida para a inserção da temática "gênero e sexualidade" nas instituições de ensino no âmbito nacional se configura com a aprovação dos Parâmetros Curriculares Nacionais - PCN de 1997, ao abordar a problemática como um dos Temas Transversais Pluralidade cultural, Meio ambiente, Saúde, Orientação sexual (BRASIL, 1997). Até então, não se discutia nas escolas brasileiras questões direcionadas à orientação sexual. De lá para cá, os debates têm crescido significativamente nos eventos educacionais, principalmente por ser um tema que abarca não apenas as demandas pedagógicas e sociais.

Com a realização deste estudo, constatou-se que as pesquisas que discutem gênero e sexualidade na escola têm crescido fortemente nas últimas décadas, além do grande aumento do índice de produção de estudos de caráter científico. Percebe-se também a amplitude social que as discussões em torno da temática têm despertado nos diversos âmbitos: nacional, estadual e municipal, visto que o tema tem se tornado não apenas uma discussão na área da saúde, como era identificado na década de 1980.

A questão voltada para a orientação sexual perpassa a esfera da saúde, preocupada em amenizar o crescimento do vírus do HIV e a quantidade de gravidez na adolescência, chegando ao ambiente escolar a partir do Tema transversal “Orientação sexual” em 1997.

A criação do tema transversal Orientação Sexual nos Parâmetros Curriculares Nacionais (PCNs) é outro indício da inserção deste assunto no âmbito escolar. O interesse do estado pela sexualidade da população torna-se evidente a partir desta proposta. De acordo com os PCNs, em virtude do crescimento de casos de gravidez indesejada entre adolescentes e do risco da contaminação pelo HIV, o tema Orientação Sexual criado como um dos temas transversais a ser trabalhados ao longo de todos os ciclos de escolarização. Cabe, portanto, à escola - e não mais apenas à família - desenvolver uma ação crítica, reflexiva e educativa que promova a saúde das crianças e dos adolescentes (ALTMANN, 2001, p. 576).

Com essa iniciativa, mesmo que a preocupação não estivesse em debater questões voltadas para a orientação sexual dos estudantes, e sim uma atenção à saúde, foi válida a intenção, pois colaborou para diversas outras ações que cooperaram com a inserção da temática no espaço escolar, o que até então não era visto no âmbito brasileiro. Logo “[...] após o surgimento da epidemia do HIV/AIDS e o reconhecimento da gravidez de jovens em idade 
escolar, a sexualidade se consolidou como lugar de fala em torno à ideia de prevenção" (CÉSAR, 2009, p. 38).

A instituição escolar é, notadamente, um ambiente que agrega pessoas de diferentes contextos no âmbito social, econômico, cultural, religioso, gênero, etnia, etc. Essa diversidade corroborou para que as escolas passassem a implementar ações direcionadas à reflexão sobre gênero e sexualidade nas instituições de ensino durante os vinte e três anos de existência dos Parâmetros Curriculares Nacionais. Araújo (2020a, p. 976) destaca que "ao trazer para sala de aula o tema diversidade [....] [seria] uma oportunidade de o (a) professor (a) incluir nas discussões a temática sexualidade. Assim, tal prática contribuiria para desvincular questões de ordem sexual abordadas apenas na área da saúde, superando a ideia de que as “" [... condutas sexuais que fogem da heterossexualidade são [fossem] consideradas problemas clínicos da psicologia ou da medicina" (SABAT, 2001, p. 16).

Ampliar essas discussões para além do ambiente da saúde é um avanço que marcou e tem marcado muitos desafios enfrentados pelas pessoas para tornar os debates acerca de gênero e da sexualidade mais sólidos nos mais diversos ambientes sociais. A autora Guacira Lopes Louro (2008) destaca que "o desafio maior talvez seja admitir que as fronteiras sexuais e de gênero vêm sendo constantemente atravessadas e o que é ainda mais complicado admitir que o lugar social no qual alguns sujeitos vivem é exatamente $a$ fronteira" (LOURO, 2008, p. 21).

Infelizmente, percebe-se que a temática da orientação sexual nas ações pedagógicas tem diminuído significativamente nos últimos anos. Essa realidade ficou mais evidente com a aprovação da Base Nacional Comum Curricular, em 2017, que omite a necessidade de discutir tamanha problemática nos espaços escolares. Com a realização desta pesquisa foi constatada essa declinação, como é perceptível na Figura 2.

Figura 2: Gênero, Sexualidade e Gênero 'e’ Sexualidade na BNCC 


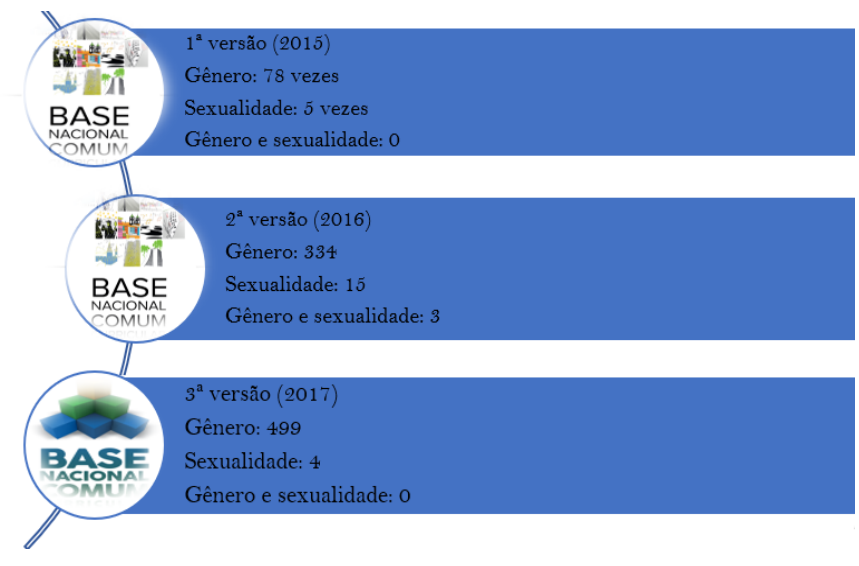

Fonte: Dados da pesquisa.

Ao observar a Figura 2, constata-se a crescente quantidade do uso do termo gênero nos três documentos. Na primeira versão, em 2015, setenta e oito vezes; em 2016, na segunda versão, trezentos e trinta e quatro; e na última e atual BNCC, de 2017, o termo gênero aparece no documento quatrocentos e noventa e nove vezes. $O$ índice de expansão seria algo a se comemorar se todos esses termos estivessem relacionados apenas às questões de orientação sexual. Mas não é essa a realidade identificada na busca nos documentos, ambos trazem outros conceitos relacionados ao termo gênero.

Na primeira versão da BNCC (2015), o termo aparece, de início, nas páginas 7, 19 e 68, apresentando uma ligação direta com as temáticas voltadas às orientações sexuais, enfatizando o respeito ao próximo e à diversidade, como é identificado em um dos objetivos para a Educação Básica, que visa:

Desenvolver, aperfeiçoar, reconhecer e valorizar suas próprias qualidades, prezar e cultivar o convívio afetivo e social, fazer-se respeitar e promover o respeito ao outro, para que sejam apreciados sem discriminação por etnia, origem, idade, gênero, condição física ou social, convicções ou credos (BRASIL, 2015, p. 7, grifo nosso).

Os demais significados estão direcionados ao trabalho com a área da Língua Portuguesa, no uso da tipologia textual, do gênero discursivo, do gênero literário, argumentativo etc. Ou seja, das setenta e oito vezes, apenas três oportunizam a inserção de implementar práticas voltadas ao trabalho com a diversidade sexual no ambiente escolar. Mesmo com um número baixo, é relevante destacar que a primeira versão do documento abordava a temática com mais pontualidade, o que não é identificado nas demais versões.

Na sequência da análise da primeira versão, o conceito de gênero enfatiza a formação do aluno, tendo como suporte o trabalho pedagógico, devendo "[...] incluir a formação pela 
criança de uma visão plural de mundo e de um olhar que respeite as diversidades culturais, étnico-raciais, de gênero, de classe social das pessoas [...]" (BRASIL, 2015, p. 19).

Na segunda versão do documento (2016), gênero aparece trezentos e trinta e quatro vezes. Porém, somente as páginas 34, 56, 68, 70, 71, 77 e 80 refletem questões de orientação sexual, oportunizando o respeito, a diversidade, a valorização e a convivência com as diferenças (BRASIL, 2016). Nos "Direitos à aprendizagem e ao desenvolvimento que se afirmam em relação a princípios éticos" (BRASIL, 2016, p. 34), o termo, assim como na primeira versão, possibilita os debates voltadosà diversidade, partindo do direito:

Ao respeito e ao acolhimento na sua diversidade, sem preconceitos de origem, etnia, gênero, orientação sexual, idade, convicção religiosa ou quaisquer outras formas de discriminação, bem como terem valorizados seus saberes, identidades, culturas e potencialidades, reconhecendo-se como parte de uma coletividade com a qual devem se comprometer (BRASIL, 2016, p. 34, grifo nosso).

Inclusive, o termo orientação sexual é encontrado na segunda versão da Base Curricular (2016), como está destacado na citação acima, sendo outro indicador de que a segunda versão, além de contemplar mais vezes o termo gênero, amplia a oportunidade discursiva no ambiente escolar. Concluindo a análise das duas versões, o mesmo procedimento foi realizado na versão final do documento que está em vigor no Sistema Educacional Brasileiro - SEB.

$\mathrm{Na}$ atual versão da BNCC (2017), o termo gênero consta quatrocentos e noventa e nove vezes, há o crescimento considerável em relação à primeira versão (2015), acompanhando o aumento da segunda versão (2016). O grande diferencial da versão três para com as demais versões está no sentido que o termo gênero traz no decorrer do documento. $\mathrm{O}$ conceito de gênero aparece nas áreas de Língua Portuguesa, Arte, Língua Inglesa e Geografia, voltados para o gênero textual, gênero do discurso, musical, cartográfico e diversidade de textosna Base Curricular (2017). Seguindo, dessa forma, na mesma linha das duas versões anteriores, porém nas versões antecedentes (2015 e 2016), o termo aparece algumas vezes replicado para os assuntos da orientação sexual.

Conclui-se, portanto, que o termo gênero, estando direcionado à orientação sexual na Base Nacional Comum Curricular, foi banido, mesmo sendo usado quatrocentos e noventa e nove vezes, em nenhuma das vezes eleestá relacionado com as inquietações sobre a diversidade. Outro dado interessante é a ausência do termo gênero no componente curricular de Ciências da Natureza, uma área diretamente ligada com as questões biológicas, sexuais, com transformações do corpo, etc. 
Ao finalizar a procura do termo gênero nas três versões da BNCC, percebe-se a exclusão do conceito de gênero direcionado às questões de orientação sexual, como uma característica da diversidade presente na sociedade. No Gráfico 1 é possível identificar o panorama evidenciado da extinção das questões de gênero com caráter de orientação sexual nos documentos oficiais da educação nacional, trazido para análise documental neste artigo.

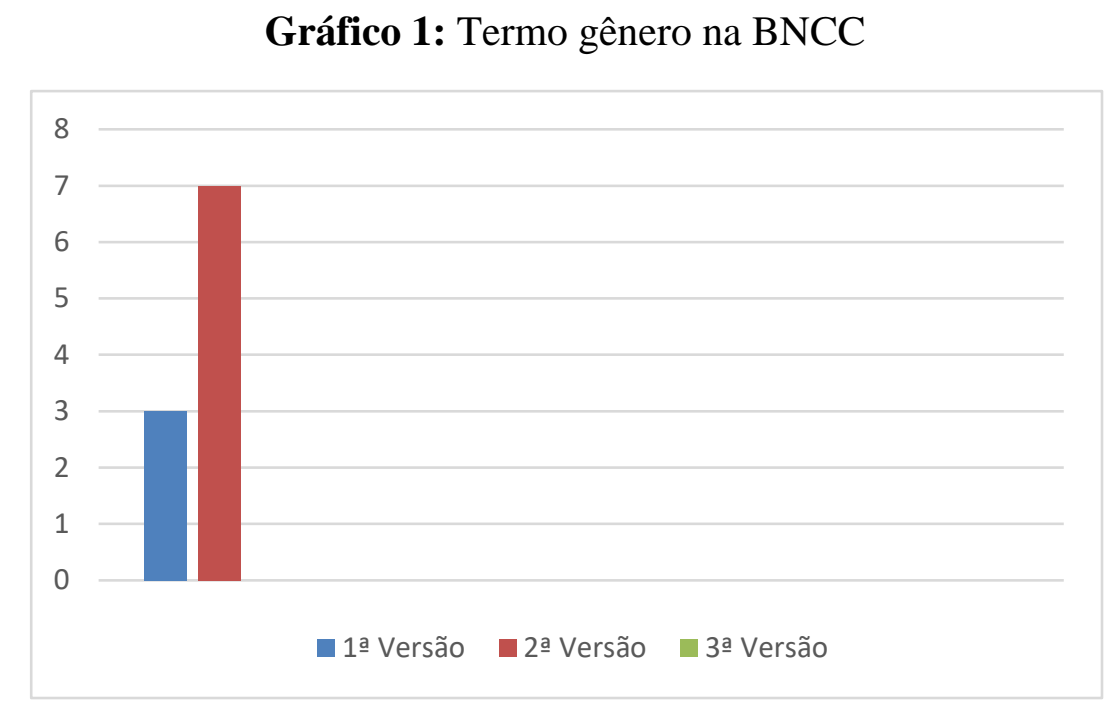

Fonte:Dados da pesquisa.

As discussões em torno do conceito de gênero não são temáticas debatidas recentemente, porém essas reflexões se fazem necessárias em virtude das diferenças de definições que o termo apresenta semanticamente. Tal variedade é percebida na análise dos documentos, pois a busca constatou que além do termo gênero contemplar questões de masculino e feminino, ainda existem outros significados. Os demais significados estão cotidianamente presentes nas relações sociais, merecendo ser discutidos, afinal é "indispensável observar que, hoje, multiplicaram-se os modos de compreender, de dar sentido e de viver os gêneros e a sexualidade" (LOURO, 2008, p. 19).

\begin{abstract}
Dizer que gênero é uma norma não é exatamente o mesmo que dizer que existem visões normativas de feminilidade e masculinidade, mesmo que tais visões normativas claramente existam. Gênero não é exatamente o que alguém "é" nem é precisamente o que alguém "tem". Gênero é o aparato pelo qual a produção e a normalização do masculino e do feminino se manifestam junto com as formas intersticiais, hormonais, cromossômicas, físicas e performativas que o gênero assume (BUTLER, 2014, p. 253, grifos da autora).
\end{abstract}

Em prosseguimento às buscas, tendo como recurso o fichamento cronológico, na segunda etapa - [Des]construção do texto -, proposto pelo Método Pragmático, foi realizada 
a procura do termo sexualidade nos três documentos, continuando com a mesma sequência, $1^{\mathrm{a}}, 2^{\mathrm{a}}$ e $3^{\mathrm{a}}$ versão. Reitere-se que na primeira versão da BNCC, o termo sexualidade aparece cinco vezes; na segunda versão, ele aparece quinze vezes; e na última versão retorna para mesma quantidade da primeira versão, aparecendo cinco vezes, conformea Figura 2.

Historicamente, a sexualidade sempre foi considerada um tabu social e familiar que, muitas vezes, era ou ainda édeixada para ser discutida apenas na vida adulta, visto que o termo sexualidade sempre esteve atrelado ao conceito de sexo. Em vista disso, Louro (2000) pontua:

Que a sexualidade era um assunto privado, alguma coisa da qual deveria falar apenas com alguém muito íntimo e, preferencialmente, de forma reservada. A sexualidade - o sexo, como se dizia - parecia não ter nenhuma dimensão social, era um assunto pessoal e particular que, eventualmente, se confidenciava a uma amiga próxima (LOURO, 2000, p. 7).

Na primeira versão da Base Curricular (2015), o termo sexualidade aparece cinco vezes, necessariamente nas páginas 86, 182, 185, 187, 200 e 300, sempre abarcando as questões de identidade e orientação sexual. Como contexto histórico, social e cultural, o termo também retoma a questão do respeito, como é identificado nos “objetivos gerais do componente curricular de Arte para a Educação Básica” (BRASIL, 2015, p. 85). Os alunos devem "conhecer, fruir e analisar criticamente diferentes práticas e produções artísticas e culturais do seu entorno social e em diferentes sociedades, em distintos tempos e espaços, respeitando as diferenças de etnia, gênero, sexualidade e demais diversidades" (BRASIL, 2015, p. 86).

Outro dado importante que a primeira versão da BNCC (2015) pontua é o surgimento do termo homossexualidade. Nesse sentido, na página 200 refere-se às questões biológicas de forma a "compreender que o fenótipo resulta de complexas relações entre processos genéticos, epigenéticos e ambientais no contexto das explicações para características comportamentais humanas que têm sido propagadas, a partir de visões deterministas biológicas" (BRASIL, 2015, p. 200).

O termo homossexualidade foi identificado durante a busca pelo termo sexualidade, em virtude da palavra sexualidade constar no termo homossexualidade, dessa forma, durante a realização do comando $(\mathrm{Ctrl}+F)$, destacou-se no documento a palavra homossexualidade, que não era o termo especificamente pesquisado. Entretanto, está atrelado às questões de sexualidade. Inclusive, o próprio documento usa o termo homossexualidade como forma de sugestão para a inserção que inquietações acerca do conceito de homossexualidade, para que o termo esteja presente em sala de aula. 
A relação complexa entre estes processos pode ser abordada por meio dos resultados de experimentos de normas de reação com linhagens de plantas geneticamente idênticas, crescidas em ambientes distintos. A partir desse ponto poderão ser discutidas questões sobre características humanas, tais como, as diferentes explicações para homossexualidade; ou os resultados de experimentos com gêmeos idênticos que se desenvolveram em ambientes culturais e sociais distintos (BRASIL, 2015, p. 200).

Ao retomar os debates sobre o termo sexualidade, a busca prosseguiu na segunda versão do documento (2016), onde foi identificado quinze vezes, necessariamente nas páginas 70, 150, 237, 239, 318, 321, 368, 397, 399, 446, 447, 484, 485, 545 e 597. É interessante sublinhar que o termo sexualidade, em ambas as páginas, está alistado às relações de gênero, corpo, orientação sexual, identidade e diversidade. "O corpo expresso e carrega consigo não somente características físicas e biológicas, mas também marcas de nosso pertencimento social que repercutem em quem somos e nas experiências que temos em relação ao gênero, à etnia ou à raça, à classe, à religião e à sexualidade" (BRASIL, 2016, p. 70).

Culturalmente, a sexualidade é algo muito vinculado ao corpo, ao biológico, ao sexo, ao prazer. Essa relação tem, certamente, contribuído para a não discussão do termo nos ambientes escolar e familiar. No espaço escolar deixa-se apenas para debater o tema nas aulas de Ciências da Natureza e Biologia; na instituição familiar, o debate acontece em raríssimos momentos, onde as meninas conversam com as mães e os meninos raramente têm a oportunidade de dialogar com os pais.

\footnotetext{
Através de processos culturais, definimos o que é — ou não — natural; produzimos e transformamos a natureza e a biologia e, consequentemente, as tornamos históricas. Os corpos ganham sentido socialmente. A inscrição dos gêneros feminino ou masculino — nos corpos é feita, sempre, no contexto de uma determinada cultura e, portanto, com as marcas dessa cultura. As possibilidades da sexualidade — das formas de expressar os desejos e prazeres - também são sempre socialmente estabelecidas e codificadas. As identidades de gênero e sexuais são, portanto, compostas e definidas por relações sociais, elas são moldadas pelas redes de poder de uma sociedade (LOURO, 2000, p. 9).
}

A falta de espaço para o diálogo no ambiente familiar tem, sobremaneira, contribuindo para que os adolescentes busquem informações para sanar seus questionamentos nas relações sociais, entretanto, isso contribui com a compreensão errônea e distorcida do termo sexualidade. Assim sendo, corroboram com a ideia cultural de que sexo e sexualidade são sinônimos e, portanto, com o processo de construção da identidade. 
O biológico e o corpo estiveram e estão vinculadas consecutivamente com as concepções de identidade, tornando-se uma demarcação de identidade de gênero, sexual ou etnia, como as "marcas" biológicas".

Talvez devêssemos nos perguntar, antes de tudo, como determinada característica passou a ser reconhecida (passou a ser significada) como uma "marca" definidora da identidade; perguntar, também, quais os significados que, nesse momento e nessa cultura, estão sendo atribuídos a tal marca ou a tal aparência (LOURO, 2000, p. 8).

Na terceira versão da BNCC (2017), o conceito de sexualidade é pontuado quatro vezes, mas em apenas três páginas: 327, 348 e 349, todas na área de Ciências da Natureza, na "Unidade temática - Vida e evolução" (BRASIL, 2017, p. 326). Essa unidade temática está recortada para a turma do oitavo ano do Ensino Fundamental, fase em que os estudantes estão na faixa etária de quatorze anos de idade. Segundo as orientações que a atual Base Nacional Comum Curricular (2017) apresenta, as discussões sobre sexualidade só devem aparecer no último ano do Ensino Fundamental. Dessa forma, até chegar aos quatorze anos de idade, as instituições de ensino ficam impossibilitadas de implementar debates sobre sexualidade em seu contexto escolar. A "Unidade temática - Vida e evolução", à qual o termo sexualidade está vinculado:

Propõe o estudo de questões relacionadas aos seres vivos (incluindo os seres humanos), suas características e necessidades, e a vida como fenômeno natural e social, os elementos essenciais à sua manutenção e à compreensão dos processos evolutivos que geram a diversidade de formas de vida no planeta (BRASIL, 2017, p. 326).

Reprodução é a relação encontrada ao identificar o termo sexualidade, intensificando as reflexões de que sexo e sexualidade são sinônimos, portanto, vinculados à reprodução humana, centrado na figura do homem e da mulher. Essas relações contribuíram com a constituição de "[...] um modelo reprodutivo que enfatizava a existência de dois corpos marcadamente diferentes, a radical oposição das sexualidades masculina e feminina, o ciclo reprodutivo automático da mulher e sua falta de sensação sexual" (LOURO, 2000, p. 40).

Dessa maneira, conclui-se a segunda etapa da busca pelos termos: gênero, sexualidade, gênero e sexualidade nas três versões da BNCC. Abaixo, no Gráfico 2, encontra-se explícita a presença do termo sexualidade nos documentos.

\section{Gráfico 2: Termo sexualidade na BNCC}




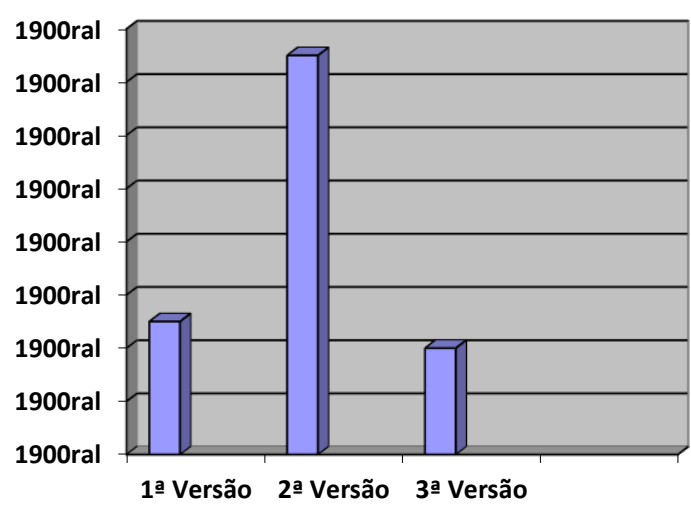

Fonte: Dados da pesquisa.

Como apresentado anteriormente no Gráfico 2, fechando a busca pelos três termos, constou-se que apenas na segunda versão da BNCC (2016) os termos gênero e sexualidade aparecem interligados, possibilitando discussões sobre a temática e não apenas como termos separados. O conceito"gênero e sexualidade" pode ser encontrado de forma uníssona nas páginas 318, 484, 485 da versão dois da Base Curricular (2016); nos demais documentos é inexistente a junção de gênero 'e' sexualidade.

É importante ressaltar que a busca se deu a partir do desejo de provocar reflexões sobre a problemática, a fim de intensificar os debates sobre três termos distintos, porém, interligados: gênero - sexualidade - gênero e sexualidade. As discussões acerca das três terminologias serão realizadas mais apuradamente na seção seguinte, com a mesma estratégia de provocar reflexões acerca das mesmas, compreendendo que não são sinônimos.

Entende-se que dos três documentos analisados, a segunda versão apresentava uma maior oportunidade para que as instituições de ensino, no âmbito nacional, implementassem discussões acerca das questões de gênero 'e' sexualidade vinculadasàs inquietações sobre orientação sexual. Portanto, contribuindo com a proliferação do respeito à diversidade humana que abarca as mais diversas esferas sociais da sociedade brasileira.

Com a realização das três etapas de análise propostas pelo Método Pragmático Construção, [Des]construção e [Re]construção dos dados (ARAÚJO, 2021, p. 75), foi possível constituir uma Proposta Curricular como um artefato para possibilitar que as escolas brasileiras levem para o espaço escolar reflexões sobre gênero 'e' sexualidade, mesmo tendo um documento norteador para elaboração das Propostas Pedagógicas e Curriculares que não 
abarca essa possibilidade. Na próxima seção, a Proposta Curricular de implementação da disciplina "Educação para a sexualidade" será apresentada com mais especificidade.

\section{Dispositivo curricular}

Como mecanismo para ampliar e, em muitas situações, inserir as questões de gênero e sexualidade no espaço escolar, foi elaborado uma prescrição com as características de uma Proposta Curricular, tendo como temática central as inquietações sobre orientação sexual. Na Figura 3 encontra-se estruturado um planejamento para tornar a Educação para sexualidade uma disciplina na área diversificada do currículo da Educação Básica. O componente curricular pode ser incluído na parte diversificada do currículo, mesmo não existindo no âmbito nacional a obrigatoriedade para que as escolas desenvolvam um trabalho disciplinar (pensando o termo enquanto disciplina curricular), onde as instituições de ensino podem integrar a disciplina "Educação para a sexualidade"enquanto componente curricular diversificado.

Figura 3: Proposta para inserir discussões sobre orientação sexual no ambiente escolar

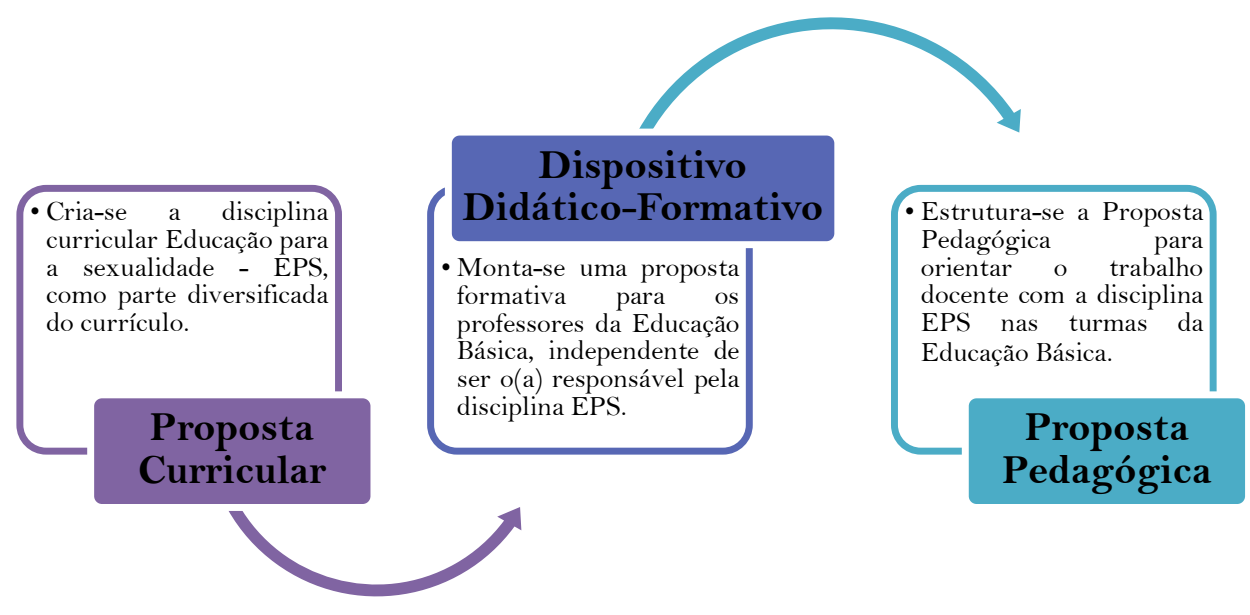

Fonte:Dados da pesquisa.

Para a efetivação da Proposta Curricularno âmbito escolar, Figura 3, a gestão, direção e coordenação deverão mobilizar esforços, apresentando a proposta para a comunidade escolar - pais, alunos e funcionários -, possibilitando que todos reflitam o quanto é preciso ações mais efetivas que contemplem essa realidade social e também escolar. Os passos seguintes são: (1) encaminhar a proposta para o Conselho escolar; (2) reformular o Projeto Político 
Pedagógico - PPP; (3) elaborar ou reformular a Proposta Curricular - PC; (4) planejar/replanejar a Proposta Pedagógica - PP.

As áreas administrativa e pedagógica deverão organizar-se para oferecer estratégias didáticas e formativas para que o professor tenha suporte ao desenvolver suas aulas, e não apenas incluir a disciplina como 'obrigatória', mesmo que na parte diversificada. Conforme garantia da Lei de Diretrizes e Bases da Educação Nacional - LDB, nº 9.394/1996, no Art. 26:

Os currículos da educação infantil, do ensino fundamental e do ensino médio devem ter uma base nacional comum, a ser complementada, em cada sistema de ensino e em cada estabelecimento escolar, por uma parte diversificada, exigida pelas características regionais e locais da sociedade, da cultura, da economia e dos educandos (BRASIL, 2017, p. 19).

Com base nas autoras Ramos e Aquino (2015, p. 241) “[...] a parte diversificada, onde podem ser incluídas disciplinas de livre escolha das escolas e dos sistemas de ensino, podendo ser, por exemplo: educação ambiental, dança de salão, informática, música, [orientação sexual], etc.”. Respaldado no Art. 26 da LDB n 9.394/1996, as instituições de ensino podem incluir as questões de orientação sexual como uma disciplina na parte diversificada, assegurada legalmente e alicerçada pelas necessidades que o ambiente escolar tem contemplado.

Todo esse processo é possível em virtude da autonomia das escolas. Mesmo sendo uma instituição alicerçada pelo poder hierárquico, ela também usufrui ou deveria usufruir dessa prerrogativa legal que lhe garante o direito de criar seus mecanismos pedagógicos, curriculares e administrativos, tendo como referência a realidade da comunidade na qual ela está inserida.

Pensar em autonomia escolar não é descentralizar o poder administrativo de um sistema de ensino, seja nacional, estadual ou municipal. A autonomia aqui discutida está vinculada ao poder de participação da comunidade escolar. "O tema da autonomia aparece na literatura acadêmica, em alguns casos, vinculado à ideia de participação social, e, em outros, vinculado à ideia de ampliação da participação política no que tange à descentralização e desconcentração do poder” (MARTINS, 2002, p. 208).

Logo, o processo de incluir uma demanda social como uma disciplina diversificada no currículo escolar não é algo fácil, porém, vem a cada dia tornando-se necessário em virtude das demandas sociais que a escola tem tido. Esse direito fica assegurando no Art. 12 da LDB n 9.394/1996 ao garantir que "os estabelecimentos de ensino, respeitadas as normas comuns 
e as do seu sistema de ensino, terão a incumbência de: I - elaborar e executar sua proposta pedagógica" (BRASIL, 2017, p. 14).

A proposta aqui apresentada não visa a inserção da disciplina Educação para sexualidade - EPS apenas em uma unidade de ensino, e sim em um Sistema de Ensino. Propõe-se para uma instituição como modelo de inserir no cenário escolar a possibilidade da criação de mecanismos que contemplem as discussões sobre a orientação sexual enquanto um componente curricular, visto que, no âmbito nacional, esse debate tem sido marginalizado pela atual gestão.

A intenção com esse dispositivo curricular é ampliar as discussões sobre gênero e sexualidade, diversidade e orientação sexual no ambiente escolar, sem que essa realidade humana esteja presente apenas em esporádicos projetos pedagógicos uma vez por ano. Portanto, é de extrema relevância a discussão diária acerca dos temas, permitindo que os estudantes participem ativamente desses debates relacionados às suas experiências dentro e fora do espaço escolar.

\section{Revisão de literatura}

O ponto de partida para a inserção das questões voltadas para gênero, sexualidade, gênero e sexualidade encontrava-se aglutinado no Tema transversal - Orientação sexual no cenário educacional brasileiro, o qual é influenciado pelos Parâmetros Curriculares Nacionais - PCN de1997. Até então não se discutiam essas inquietações no espaço escolar, visto que o foco estava sempre na área da saúde, em função de questões específicas como o crescimento do vírus do HIV/Aids e das adolescentes que estavam engravidando precocemente.

É pertinente destacar que, nessa época, a preocupação estava na sexualidade, como destaca César (2009, p. 38) ao afirmar que "nos últimos vinte anos, após o surgimento da epidemia do HIV/AIDS e o reconhecimento da gravidez de jovens em idade escolar, a sexualidade se consolidou como lugar de fala em torno à ideia de prevenção". Por consequência dessa demanda social, os Parâmetros trazem os assuntos de orientação sexual para o ambiente escolar em forma de Temas Transversais.

Sobre esse assunto, Garcia, Garcia e Paula (2012) sinalizam que os temas elencados como Temas Transversais,

[...] Têm como objetivo discutir temas atuais de abrangência nacional como Ética, Meio Ambiente, Orientação Sexual, Pluralidade Cultural, Saúde e Trabalho e Consumo, para uma maior participação ativa na sociedade, gerando 
questionamentos e proposições de mudanças no nosso país (GARCIA; GARCIA; PAULA, 2012, p. 12).

A inclusão dos PCN (1997) nos espaços escolares foi uma das formas de atender uma maior gama de discussões que integra as relações humanas e que o currículo não estava ou não está dando conta de contemplar em suas disciplinas. "Os PCN nos põem de novo diante de um problema antigo na área do currículo: as disciplinas tradicionais não dão conta de um conjunto de questões postas pela realidade vivida pelos alunos" (MOREIRA, 1999, p. 43-44).

Com a inclusão das questões sobre orientação sexual, a partir da institucionalização dos Parâmetros Curriculares na década de 1990, apoiado nas discussões dos Temas transversais, oportunizava-se a inclusão de temáticas emergidas das diversas situações sociais, e os debates relacionados à sexualidade já se faziam presentes na Europa no século XIX, "quando a vida regrada dos colégios estabelecera um conjunto de regras sobre o corpo de jovens e crianças" (CÉSAR, 2009, p. 38). Nessa época, Michel Foucault (1988) problematizava os espaços escolares como “[...] regulamentos elaborados para a vigilância do recolhimento e do sono, tudo fala da maneira mais prolixa da sexualidade das crianças" (FOUCAULT, 1988, p. 30).

Atualmente, a sexualidade é algo bastante difícil de diálogo nas instituições familiares e escolares, deixando a cargo da instituição educacional debater o tema, onde acaba,por vezes, sendo propagados conceitos e interpretações equivocadas. "Hoje, tal como antes, a sexualidade permanece como alvo privilegiado da vigilância e do controle das sociedades. Ampliam-se e diversificam-se suas formas de regulação, multiplicam-se as instâncias e as instituições que se autorizam a ditar-lhe normas" (LOURO, 2008, p. 21).

A autora Judith Butler (2014) disserta que:

\begin{abstract}
A sugestão de que gênero é uma norma requer maiores elaborações. Uma norma não é o mesmo que uma regra, e não é o mesmo que uma lei. Uma norma opera no âmbito de práticas sociais sob o padrão comum implícito da normalização. Embora uma norma possa ser analiticamente separada das práticas nas quais ela está inserida, também pode mostrar-se recalcitrante a quaisquer esforços de descontextualização de sua operação. Normas podem ou não serem explícitas, e quando elas operam como o princípio normalizador da prática social, elas geralmente permanecem implícitas, difíceis de perceber e mais clara e dramaticamente discerníveis nos efeitos que produzem (BUTLER, 2014, p. 252).
\end{abstract}

A diversidade do conceito de gênero, algo ainda confuso para muitas pessoas, tem ganhado bastante atenção, tanto nos eventos educacionais quanto nas pesquisas acadêmicas. Afinal, "no terreno dos gêneros e da sexualidade, o grande desafio, hoje, parece não ser apenas 
aceitar que as posições se tenham multiplicado, então, que é impossível lidar com elas a partir de esquemas binários (masculino/feminino, heterossexual/homossexual)" (LOURO, 2008, p. 21). A autora continua enfatizando que "o gênero se constitui com ou sobre corpos sexuados, ou seja, não é negada a biologia, mas enfatizada, deliberadamente, a construção social e histórica produzida sobre as características biológicas" (LOURO, 1997, p. 6).

As inquietações e reflexões acerca da problemática da orientação sexual abarcam tamanha relevância, que têm se tornado uma problemática de intensos debates não apenas na área da saúde, à qual sempre esteve atrelada. Os debates sobre gênero e sexualidade chegam ao espaço escolar acoplados ao termo orientação sexual, levando para o espaço escolar a oportunidade de discutir tal demanda social. A expansão das questões de orientação sexual adentra o ambiente escolar "no final do século passado" (MAIA, 2004, p. 153).

\begin{abstract}
As questões do acesso à orientação sexual e a discussão da saúde e da sexualidade deveriam ser um direito assegurado a todas as pessoas. Esse direito deveria ser incluído nas propostas educativas em diferentes instituições educacionais e estendido a todos os cidadãos, não como um favor feito para indivíduos à parte do contexto e do grupo social, numa dada cultura, em que o sujeito vive, mas sim como consequência da luta das minorias excluídas e por isso com uma dimensão histórica e social (MAIA, 2004, p. 153-154).
\end{abstract}

Acredita-se que a criação da disciplina Educação para sexualidade - EPS, para as turmas da Educação Básica, seria uma das formas de inserir as discussões sobre gênero, sexualidade, e sobre gênero ' $\mathrm{e}$ ' sexualidade no ambiente escolar, visto que as discussões são escassas nos documentos oficiais no âmbito nacional, exceto no Parâmetro Curricular Nacional (1997) que trata dos Temas transversais. Dessa forma, uma das possibilidades seria regulamentar a disciplina EPS na parte diversificada dos currículos.

Vale lembrar que a parte diversificada do currículo escolar é exatamente a oportunidade que as instituições de ensino regular têm para incluir em suas Propostas Curriculares discussões que contemplem temáticas direcionadas às orientações sexuais de seus estudantes. Essa lacuna que as escolas têm está legalmente assegurada por lei que garante a autonomia das escolas para incluírem problemáticas emergentes da comunidade local na qual a escola está inserida, e não apenas situações oriundas de outras realidades.

A intencionalidade dos Temas Transversais é exatamente essa, levar para o ambiente escolar situações sociais que merecem discussão como uma estratégia de contribuir com tamanha relevância (BRASIL, 1997). Ressalte-se que assim como as inquietações sobre orientação sexual que é um dos Temas Transversas, o PCN elenca outros, como, por exemplo, 
a problemática da Educação para o trânsito, que não é uma realidade apenas dos grandes centros urbanos.

Assim como a "Educação para o trânsito" tem merecido destaque nos últimos anos, mesmo de forma lenta, é significante destacar que a orientação sexual não é mais uma questão da área da saúde e das cidades mais desenvolvidas. As discussões sobre Educação para o trânsito estão melhor discutidas na dissertação "A formação docente e a prática de Ensino Investigativo nas aulas de Ciências Naturais como perspectiva à Alfabetização Científica", de autoria de Araújo (2020). O autor trata exatamente da importância da inserção da temática "Educação para o trânsito" no ambiente escolar.

Espera-se, portanto, que este trabalho possa contribuir de modo considerável ao se pensar as inquietações que abarcam as problemáticas nele discutidas, sobretudo no que se refere à possibilidade de criação das disciplinas Educação para a sexualidade - EPS e a Educação para o trânsito - EPT. Dito isso, defende-se que elas passem a integrar as Propostas Curriculares das instituições de ensino da Educação Básica como uma das formas de transpor interpretações equivocadas sobre a diversidade humana e as necessidades sociais.

\section{Considerações finais}

O processo de $[\mathrm{Re}]$ construção dos dados proposto pelo Método Pragmático foi, notadamente, fundamental para constituir a Proposta Curricular de incluir a disciplina Educação para a sexualidade nas turmas da Educação Básica, como uma parte diversificada do currículo das instituições de ensino no âmbito nacional. Nas reflexões durante a [Re]construção dos dados foi possível perceber o quanto os conceitos de gênero, sexualidade e gênero e sexualidade são omitidos na Base Nacional Comum Curricular que normatiza as Propostas Curriculares e Pedagógicas das escolas brasileiras.

Ao final do estudo, constata-se que as questões de gênero, sexualidade e gênero e sexualidade, compiladas às problemáticas de orientação sexual, merecem ser enfrentadas com maior serenidade pelos envolvidos com o Sistema Educacional Brasileiro. Debater essas questões não é mais responsabilidade da área da saúde, e sim um problema social. Por esse motivo a educação não deve ficar omissa a essas demandas, afinal, o processo educacional está entrelaçado por temas que perpassam apenas a aquisição de habilidades conceituais.

Na contemporaneidade, as exigências por uma formação mais holística do estudante têm crescido. Tais exigências possibilitam-no adquirir e desenvolver as mais variadas competências enquanto sujeito mais participativo, questionador, ativista e integrador do 
processo de transformação social, visto que abarcam uma gama de demandas que têm crescido mediante os avanços passados pela sociedade ao longo dessas últimas décadas.

É dessa realidade que emergiu a problemática discutida durante o artigo. Realidade esta que, após ser analisada, reafirma a escassez dos termos pesquisados nas três versões da BNCC, (2015), (2016) e (2017), principalmente na versão final da Base (2017); e que desaceita explicitamente a realidade assoladora que afeta o ambiente escolar, as relações sociais dos indivíduos, impactando direta e indiretamente no sistema educacional brasileiro.

\section{Referências}

ALTMANN, Helena. Orientação sexual nos Parâmetros Curriculares Nacionais. Estudos feministas, a. 9, set. 2001.

ARAÚJO, Luiz Carlos Marinho de. A formação docente e a prática de ensino investigativo nas aulas de Ciências Naturais como perspectiva à Alfabetização Científica. Dissertação de Mestrado - Universidade Estadual do Sudoeste da Bahia. Programa de Pós-Graduação Educação Científica e Formação de Professores, Campus, Jequié/BA, 2020.

ARAÚJO, Luiz Carlos Marinho de.O livro didático do Ensino Fundamental e as discussões de sexualidade nas aulas de Ciências Naturais. Revista Mais Educação, v. 3, n. 5, julho, 2020a.

ARAÚJO, Luiz Carlos Marinho de.Método Pragmático: da construção à [re]construção dos dados. 1 ed. Curitiba: Editorial Casa, 2021.

BARDIN, Lourence. Análise de conteúdo. São Paulo: Edições 70, 2016.

BRASIL, Base Nacional Comum Curricular. Ministério da educação - MEC, Brasília, $1^{\circ}$ versão, 2015. versão, 2016.

Base Nacional Comum Curricular. Ministério da educação - MEC, Brasília, $2^{\circ}$ , Base Nacional Comum Curricular. Ministério da educação - MEC, Brasília, $3^{\circ}$ versão, 2017.

, $L D B$ : Lei de Diretrizes e Bases da Educação Nacional.Edição atualizada até março de 2017, Brasília: Senado Federal, Coordenação de Edições Técnicas, 2017.

,Parâmetros Curriculares Nacionais: pluralidade cultural, orientação sexual. 1997.

BUTLER, Judith. Regulações de Gênero.Cadernos pagu,jan.jun, 2014.

CÉSAR. Maria Rita de Assis. Gênero, sexualidade e educação: notas para uma "Epistemologia". Educar, Editora UFPR, Curitiba, n. 35, p. 37-51, 2009. 
FOUCAULT, Michel. História da sexualidade I: A vontade de saber, tradução de Maria Thereza da Costa Albuquerque e J. A. Guilhon Albuquerque. Rio de Janeiro, Edições Graal, 1988.

FRANCELIN, Marivalde Moacir. Fichamento como método de documentação e estudo. In: SILVA, José Fernando Modesto da; PALETTA, Francisco Carlos (org.). Tópicos para o ensino de biblioteconomia, v. 1. São Paulo: ECA-USP. 2016.

GARCIA, Maria Helena Casas; GARCIA, Michelle Neves; PAULA, Rosemeire Lima de. Temas Transversais: a abordagem pelos professores de língua materna no ensino fundamental em sala de aula. Revista Eletrônica. 2012.

GODOY, Arilda Schmidt. Pesquisa qualitativa: Tipos fundamentais. Revista de Administração de Empresas. São Paulo, v. 35, n. 3, mai/jun, 1995.

LOURO, Guacira Lopes.Gênero e sexualidade: pedagogias contemporâneas. Proposições, v. 19, n. 2, maio/ago. 2008.

,Guacira Lopes. Gênero, sexualidade e educação. Uma perspectiva pósestruturalista. Petrópolis: Vozes, 1997.

, Guacira Lopes. O corpo educado: Pedagogia da sexualidade. 2 ed., Belo Horizonte: Autêntica. 2000.

LÜDKE, Meng.; ANDRÉ, Marli Eliza Dalmazo Afonso. Pesquisa em educação: Abordagem Qualitativa. 2 ed. Rio de Janeiro: E.P.U, 2020.

MAIA, Ana Cláudia Bortolozzi. Orientação sexual na escola. In: RIBEIRO, Paulo Rennes Marçal (org.). Sexualidade e educação: aproximações necessárias. São Paulo: Arte e Ciências. 2004.

MARTINS, Ângela Maria. Autonomia e educação: a trajetória de um conceito. Cadernos de Pesquisa, n. 115, p. 207-232, março/ 2002.

MOREIRA, Antônio Flavio Barbosa (org.). Currículo: Políticas e Práticas. 10 ed. Campinas: Papirus, 1999.

RAMOS, Priscila da Silva; AQUINO, Katia Aparecida da Silva. Ações na parte diversificada do currículo: um relato de experiência na perspectiva de uma aprendizagem significativa crítica. Revista Cadernos de Estudos e Pesquisa na Educação Básica, Recife, v.1, n.1, p. 240 - 249, 2015.

SABAT, Ruth.Pedagogia cultural, gênero pedagogia cultural, gênero e sexualidade. Estudos feministas, a. 9, set. 2001.

\section{Notas de Referências ${ }^{i}$}


Licenciado em Pedagogia pela Faculdade de Ciências Educacionais (FACE). Especialista em Ensino de Ciências nos anos iniciais do Ensino Fundamental pela Universidade Federal do Recôncavo da Bahia (UFRB). Mestre em Educação em Ciência e Matemática pela Universidade Estadual do Sudoeste da Bahia (UESB). Doutorando em Educação em Ciências e Educação Matemática na Universidade Estadual do Oeste do Paraná (UNIOESTE), no Programa de Pós-Graduação Educação em Ciências e Educação Matemática (PPGECEM). Integrante do Grupo de Pesquisa em Educação em Ciências e Biologia (GECIBIO). Professor da Educação Básica no município de Itamari, Bahia.

ORCID: https://orcid.org/0000-0003-4385-8093

Contato: marinhoaluiz@ hotmail.com 